\title{
A NEW SPECIES OF HEYDENIA FORSTER (HYMENOPTERA: PTEROMALIDAE) FROM INDIA
}

\author{
P.M. Sureshan \\ Zoological Survey of India, Western Ghat Field Research Station, Annie Hall Road, Calicut, Kerala 673002, India
}

\begin{abstract}
A new species of the genus Heydenia: H. tuberculata is described from India.
\end{abstract}

Key words

Pteromalidae, Heydenia, new species.

\author{
F1-F7 - Funicular segments first to seventh, \\ POL - Post-ocellar distance, \\ T2 - Second gastral tergite
}

\section{Abbreviations}

OOL - Ocell-ocular distance

T1 - First gastral tergite

\section{Introduction}

The genus Heydenia Forster belongs to the subfamily Cleonyminae of Pteromalidae (Chalcidoidea), members of which are parasites of Scolytidae (Coleoptera) attacking trunks and branches of dying trees (Boucek, 1988). From India and the adjacent countries the genus is represented by an undescribed species known from Sri Lanka and India (Boucek, et al. 1979). In this paper a new species of Heydenia is described from Karnataka, India.

The type specimen is kept in the collections of Zoological Survey of India, Western Ghats Field Research Station, Calicut.

\section{Heydenia tuberculata sp. nov.}

(Figs. 1-4)

\section{Material examined:}

Holotype: Female: India: Karnataka, Coorg (Chitekanum), 4.iii.1994, Coll. P.M. Sureshan (ZSI, Calicut).

Etymology: Species name pertains to the presence of a tubercle on propodeum.

\section{Diagnostic features}

Female: Length $3.1 \mathrm{~mm}$ (including ovipositor). Head and thorax dark coppery brown merging with bright blue, especially on dorsal part of pronotum, mesoscutum and upper face; gaster dark brown except basal two-third part of ovipositor paler; broad belt across face with antennal bases covered with silvery white scales; antennae dark brown except scape paler; legs with hind coxae blackish brown, remainder dark brown with the following exceptions; fore tarsi testaceous; tips of mid and hind femora, mid and hind tibiae and mid and hind tarsi yellowish; forewing with veins brown with brown infumations and two black tufted spots as in figure 3 .

Head: (Figs. $1 \& 2$ ). Vertex narrow, $0.3 x$ the width of head. In dorsal view head width $1.7 \mathrm{x}$ length and in front view width $1.2 \mathrm{x}$ height; POL 2x OOL; frons only superficially reticulate, shiny, but parascrobal areas deeply reticulate; vertex, genae and occipital area finely reticulate with small white hairs; clypeus with anterior margin weakly emarginate; eyes bare, pear shaped, length $1.5 \mathrm{x}$ width (in profile). Antennal flagellum gradually widening towards the tip, clup widest; scape length $0.7 \mathrm{x}$ length of eye; anelli short, transverse; F1 little shorter than pedicel; F1-F4 almost equal; F5-F7 little shorter but equal; club as long as four preceeding segments combined.

Thorax: Pronotum finely reticulate dorsally, lateral parts shiny. Mesoscutum and scutellum distinctly reticulate punctate; axillae almost shiny with some piliferous punctures on sloping part; notauli distinct, almost complete. Mesoscutum width $1.7 x$ length. Scutellum length $1.13 \mathrm{x}$ width, convex, but almost flat dorsally beyond anterior half. Propodeum (Fig.4) with a ' $Y$ ' shaped median carina, with a sharp forwardly curved tubercle at the trijunction; plicae complete; median area of propodeum almost shiny, lateral parts reticulate. Prepectus almost shiny. 
Mesopleuron reticulate except for the upper mesepimeron shiny. Metapleuron reticulate punctate with dense silvery-white hairs on the lower part. Fore and hind femora enlarged; fore femora and tibia without distinct spines on the margin. Forewing as in figure 3 .

Gaster: Compressed laterally, with a short transverse petiole which is about twice as broad as long; T1 tubular, with hind margin entire; hind margin of $\mathrm{T} 2$ medially produced, hind margin of others straight; ovipositor about half as long as hind tibia.

\section{Male: Unknown}

Remarks: This species closely resembles $H$. longicollis (Cameron) and H. cristatipennis (Girault) in general morphology and nature of gaster but can be readily distinguished from these speciesin having antennal flagellum gradually widening towards the tip, ovipositor of medium length and propodeum with a distinct median ' $Y$ ' shaped carina with a curved tubercle and distinct and complete plicae (in longicollis and cristatipennis antennal flagellum slender, not widening towards the tip, ovipositor short and propodeum without a tubercle). In having an unusually shiny axillae and in the nature of forewing, it closely resembles $H$. trinodis Boucek but differs from it in having antennal flagellum widening towards tip, propodeum with distinct plicae and curved tubercle and ovipositor short, about half as long as hind tibia (in trinodis antennal flagellum hardly thickened towards tip, propodeum with plicae very weak and without curved tubercle and ovipositor long about $1.2 \mathrm{x}$ as long as hind tibia).

\section{Acknowledgements}

The author is grateful to the Director, Zoological Survey of India, Calcutta, and the Officer-in-Charge, Zoological Survey of India, Western Ghats Field Research Station, Calicut, for providing facilities and encouragement. I am also grateful to Dr.T.C. Narendran, Professor, University of Calicut, for guidence and valuable suggestions.

\section{References}

Boucek, Z. (1988). Australasian Chalcidoidea (Hymenoptera). C.A.B. International, Wallingford, U.K. pp.266-267.

Boucek, Z., B.R. Subba Rao and S.I. Farooqi (1979). A preliminary review of Pteromalidae (Hymenoptera) of India and adjacent countries. Oriental Insects 12: 433-467.

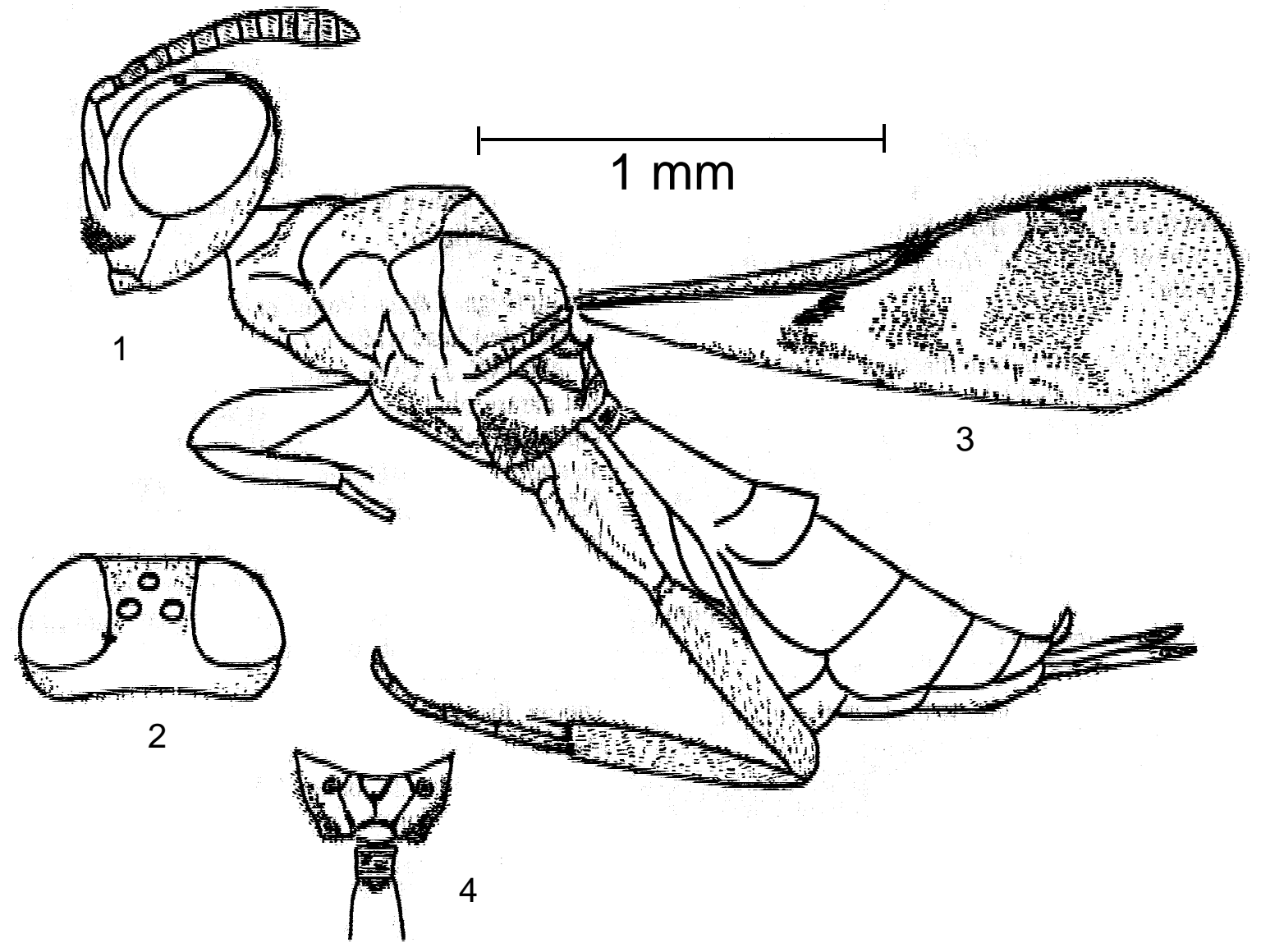

Figure 1-4. Heydenia tuberculata sp. nov. female.

1. Body in profile; 2. Head in dorsal view; 3. Forewing; 4. Propodeum with base of gaster in dorsal view. 